\title{
Die Behandlung der Dilatationen und
} Divertikel der Speiseröhre.

Von Prof. Dr. Hugo Starck in Heidelberg-Karlsruhe.

M. H.! Noch um die Jahrhundertwende wäre es mir nicht möglich gewesen, einer freundlichen Aufforderung der Redaktion folgend, einen klinischen Vortrag über obiges Thema $\mathrm{zu}$ verfassen.

Die Fälle von Divertikeln und Dilatationen, welche Ende der neunziger Jahre in meine Beobachtung gelangten, gewährten eineı entsetzlichen Anblick.

Der erste Fall von Divertikel, der 1897 in die Erbsche Klinik eingewiesen wurde, bot ein Bild der Abmagerung, wie ich es seitdem nicht mehr zu sehen bekam, und als ich etwa ein Jahr später die dem Hungertode verfallene Frau in ihrem Heimatsorte zu sezieren Gelegenheit hatte, bot diese den Anblick einer Mumie; zwischen Haut und Knochen fand sich kein Fetträubchen, die Muskulatur war auf minimalste Reste geschwunden.

Die ersten Fälle von diffusen Dilatationen, die ich untersuchte, sahen nicht viel besser aus; auch hier extremste Abmagerung, die mit Hungertod endete, wenn der letale Ausgang nicht durch Gastrostomie hinausgeschoben wurde.

Inı allgemeinen mußte die Prognose beider Krankheiten 
als infaust bezeichnet werden, wenn auch einige wenige Fälle von Divertikeln durch die Hand geschickter Chirurgen schon damals gerettet werden konnten.

Sehr erschwerend für eine Therapie fiel ins Gewicht, daß die beiden Krankheitsbilder unter den Aerzten so wenig bekannt waren, daß die früheren Fälle meist erst bei der Sektion geklärt, oder doch erst so spät diagnostiziert wurden, daß eine Behandlung versagen mußte. Heute ist die $\mathrm{S} y \mathrm{~m}$ tc $\mathrm{m}$ a tologie soweit gefördert, das Krankheitsbild so scharf gekennzeichnet, daß das Divertikel und die diffuse Dilatation $\mathrm{zu}$ den am leichtesten zu diagnostizierenden Krankheitsbildern der Speiseröhre zu zählen sind.

Aber auch die Therapie hat solche glänzenden Fortschritte zu verzeichnen, daß ein tödlicher Ausgang unbedingt vermieden werden kann, wenn die Diagnose frühzeitig gestellt ist; so sah ich wenigstens bei etwa 50 Fällen eigener Beobachtung in den letzten Jahren keinen ungünstigen Verlauf mehr. 